\title{
Genres in Scientific and Technical Rhetoric
}

\section{Carolyn R. Miller}

Department of English, North Carolina State

University

Raleigh, NC USA

\section{Jeanne Fahnestock}

Department of English, University of Maryland

College Park, MD USA

Poroi 9,1 (April 2013)

The idea of genre marks large-scale repeated patterns in human symbolic production and interaction, patterns that are taken to be meaningful. They thus can be defined by reference to pattern, or form, and by reference to theories of meaning and interaction. As a consequence, there are many ways to define genres, with some looking internally, to linguistic features and clusters of features, and others externally, to discourse communities and social interactions or recurrent rhetorical situations. Our discussion covered differences and difficulties with alternate ways of defining genres, their relevance to science and technology, explorations of the ways genres change or evolve, and pedagogical applications of genre analysis in scientific and technical discourse. ${ }^{1}$ What follows is an outline of the issues and questions that our discussion raised. We had insufficient time to consider technology separately from science, even as we recognized that it would be different.

\section{Definitions of Genre}

There was general agreement that the matter of definition is a problem. We mentioned the following approaches to definition that have had some influence:

Genre as social action: Miller (1984) defines rhetorical genres as social actions that emerge from and address recurring rhetorical situations.

Formal or descriptive definitions: These rely on a diagnostic set of features; for example, when Jamieson and Campbell (1982) argue about hybrid genres or genre origins, they use a few features as key. Their method is not rationalized. What stylistic features or suite of features should be taken as criterial? Another example is Swales's (1990) work on the scientific research report, especially the formal-functional moves needed in the introduction.

\footnotetext{
${ }^{1}$ This report is based on conversation with Steven Gibson, Carolyn
} Glasshoff, G. Thomas Goodnight, Randy Harris, and Ashley Kelly. 
Discourse community definition: Texts can bring audiences into existence who might otherwise never interact; texts can facilitate and enable community formation. Swales's work (1990) is useful here also, with his example of the catalogs with a highly specialized register that create a community interested in the postal history of Hong Kong. It's possible that the Internet has made it easier for such discourse communities to form, since geographic proximity is less necessary.

"Folk" definitions of genre: This approach is supported by the fact that there are many spontaneous terms for genres among those who produce and consume them. Miller (1984) advocates this approach as an initial approximation. The best way to get at genres in this view is to do ethnographies of their users and see how they define genres.

Legal and administered definitions: These genres created by authorities may not make sense to those who are obliged to produce or use them, as with many classroom genres and the earliest attempts to produce the Congressionally defined "Environmental Impact Statement" (Miller, 1984).

We raised some additional questions: Are there genres that are invisible to their users? Are there hierarchies of genres, that is, "generic genres" and then subgenres (for example, the biography and the subgenre autobiography and the subgenre of that, the apologia)? What kinds of questions are asked/answered at these different levels? How do we discriminate between analysis at the level of genre and analysis at the level of stylistic features, that is, features that can be in any text or in many genres, as the work of Fahnestock suggests (1999)? We also noted that in many cases these various definitions/approaches are not mutually exclusive and can be simultaneously productive.

\section{Genres in Science and Technology}

Each of the approaches to genre definition offers useful ways to approach science and technology. The assumption in much work has been that the research article is the primary genre in science, with work by Bazerman (1988), Swales (1990, 2004), and Gross (2006, Gross, Harmon, \& Reidy, 2002) proceeding from this assumption. But exploring the recurrent rhetorical actions of scientists, the structure of their discourse communities, the genre-terms they use, the forms they easily identify or that show up most frequently in a relevant corpus could lead to a focus on different genres and to different understandings of how genres structure, enable, and constrain the work of science. It might be possible to characterize science as a discourse community by mapping its system of genres; such work could also show interactions and relations among genres and the locations of power and decision making. We had less to say about the work of technology because the communities and practices are more divergent.

\section{The "Evolution" of Genres}

Questions about how genres change occupied much of our discussion, and the changes wrought in science (as well as other forms of life) by new 
digital media make these questions salient. Can genres be said to evolve? Do they evolve from other genres? From adaptation to changing rhetorical situations?

For example, how is the scientific article with its canonical IMRAD structure and importance changing due to the affordances of online publication? For instance, we are witnessing the removal of the methods section to an external database; the exporting of and reference to undigested data sets available online (until erased from some server); the counting of page views as a measure of importance versus citation records; the availability of reviewers' comments online; and incorporation by linking of video or audio evidence.

Another general topic of particular interest here was the question of how science accommodates public audiences, given the increasing access by the public to primary scientific genres through online media, as well as the increasing potential for interaction between scientific and public communities. It has been suggested, for example, that the Internet is "eroding" boundaries between science and nonscience (Trench, 2008), and this process, if true, may well be modifying genres in both the scientific and public realms.

We also raised the question of whether visual representations or multimodal constructions constitute genres or whether they are usually to be considered as components of genres. Visual genres may be entirely dependent on a particular medium in a way that verbal genres are not-as in the news photo, political cartoon, children's book illustration, etc. This issue raised the more general question of what the difference is between an affordance or medium or mode of communication and a genre? How are new genres identified? What brings them about? Clearly new research and greater conceptual clarity are needed. Historical research into the emergence of new genres in the past may be instructive.

\section{Pedagogy}

One of the most important applications of genre analysis to science and technology, we agreed, is in teaching. Students can be asked to identify genres, distinguish criterial features, and then imitate them, a process that raises the question of whether classical practices of imitatio might be implemented and adapted to instruction in scientific and technical communication. The process of apparently constant and rapid change in scientific genres may complicate the development of curriculum and teaching methods, but it could lead to productive student engagement in observational and interview fieldwork in the workplaces for which they imagine themselves to be preparing. Such work can be useful both in teaching about the nature of science as an enterprise and in teaching students to participate as novices in that work, in part by writing and speaking in the forms of interaction that constitute the scientific enterprise.

\section{References}

Bazerman, C. (1988). Shaping written knowledge: The genre and 
activity of the experimental article in science. Madison: University of Wisconsin Press.

Fahnestock, J. (1999). Rhetorical figures in science. New York: Oxford University Press.

Gross, A. G. (2006). Starring the text: The place of rhetoric in science studies. Carbondale, IL: Southern Illinois University Press.

Gross, A. G., Harmon, J. E., \& Reidy, M. (2002). Communicating science: The scientific article from the 17th century to the present. New York: Oxford University Press.

Jamieson, K. H., \& Campbell, K. K. (1982). Rhetorical hybrids: Fusions of generic elements. Quarterly Journal of Speech, 69, 146-157.

Miller, C. R. (1984). Genre as social action. Quarterly Journal of Speech, $70(2), 151-176$.

Swales, J. M. (1990). Genre analysis: English in academic and research settings. Cambridge, UK: Cambridge University Press.

----. (2004). Research genres: Explorations and applications. Cambridge, UK: Cambridge University Press.

Trench, B. (2008). Internet: Turning science communication inside-out. In M. Bucchi \& B. Trench (Eds.), Handbook of public communication of science and technology (pp. 185-198). New York: Routledge. 